Original Article

\title{
A PILOT STUDY ON IDENTIFICATION AND MANAGEMENT OF DRUG INDUCED SEXUAL DYSFUNCTION: A COLLABORATIVE APPROACH BY CLINICAL PHARMACIST AND PSYCHIATRIST
}

\author{
BILESH SHAKYA ${ }^{1}$, TIRIN BABU ${ }^{1}$, MOHAMED SHAFI P. ${ }^{1}$, VEMURI TEJASRI ${ }^{1}$, JUNY SEBASTIAN ${ }^{1}$, SHIVANANDA \\ MANOHAR J. ${ }^{2}$, JISHA MYALIL LUCCA ${ }^{3}$
}

1Department of Pharmacy Practice, JSS College of Pharmacy, JSS Academy of Higher Education and Research, Mysuru, Karnataka 570015, India, ${ }^{2}$ Department of Psychiatry, JSS Medical College and Hospital, JSS Academy of Higher Education and Research, Mysuru 570015, Karnataka, India, ${ }^{3}$ Department of Pharmacy Practice, Imam Abdulrahman Bin Faisal University, Dammam, Kingdom of Saudi Arabia Email: junysebastian@jssuni.edu.in

Received: 28 May 2019, Revised and Accepted: 10 Dec 2019

\section{ABSTRACT}

Objective: To assess the role of clinical pharmacists in the identification and management of drug-induced sexual dysfunction in collaboration with the psychiatrist and also to determine the prevalence and pattern of drug-induced sexual dysfunction, identify nature and extend of drug-induced sexual dysfunction, and assess the pattern of management of drug-induced sexual dysfunction.

Methods: This periodic prevalence interventional study was carried out among patients who visited the psychiatric department of a university hospital over three month's period. Patients were screened for sexual dysfunction using the Arizona Sexual Experience Scale (ASEX) by study pharmacists.

Results: Of the 100 patients reviewed, only $50 \%$ of subjects met the study criteria. Depression (42\%) was the most common clinical diagnosis among the study patients. The overall prevalence of drug-induced sexual dysfunction was $16 \%$. A higher incidence of drug-induced sexual dysfunction was observed in men (62.5\%). Decrease libido (40\%) was the most prominently observed drug-induced sexual dysfunction in both genders. Antidepressant $(50 \%)$ was the most common class of drugs implicated in sexual dysfunction. Drug-induced sexual dysfunction was pharmacologically managed with vaginal lubrication (40\%), Tadalafil (20\%) and Tadalafil+Dapoxetine combination (40\%).

Conclusion: With this study, provided a vision, further how prospective studies in this arena may be carried out for better understanding druginduced sexual dysfunction and how a clinical pharmacist can contribute for better health care of patients in the sex clinic by collaborating with medical practitioners.

Keywords: Sexual dysfunction, Drug-induced sexual dysfunction, Prevalence, Clinical Pharmacist's Role, Sex clinic

(C) 2020 The Authors. Published by Innovare Academic Sciences Pvt Ltd. This is an open-access article under the CC BY license (http://creativecommons.org/licenses/by/4.0/) DOI: http://dx.doi.org/10.22159/ijpps.2020v12i2.34334. Journal homepage: https://innovareacademics.in/journals/index.php/ijpps

\section{INTRODUCTION}

In Basic Need for Life Pyramid, sex comes in the third position and its dysfunction has a significant impact on the quality of life of both patient and partner [1]. Sexual dysfunction refers to a disturbance in sexual functioning, due to psychophysiological changes in the sexual response cycle of men and women [2,3]. Approximately, 43\% of women and $31 \%$ of men experience sexual dysfunction [4]. Both men and women could encounter sexual dysfunction which may be presented as low libido, lack of swelling and lubrication in women, erectile dysfunction, premature, retrograde or absent ejaculation, anorgasmia and painful sex [5]. They may be due to medical conditions, psychosocial factors or drug therapy [4].

Globally, the prevalence of drug-induced sexual dysfunction varies from $4 \%$ to $60 \%$. Classes of drug which are reported to cause sexual dysfunction are antidepressants, antipsychotics, antihypertensives and antiepileptics. The prevalence of sexual dysfunction with above mention classes of drug are $30 \%-70 \%$ with antidepressants, $30-60 \%$ with first-generation antipsychotics [2], 20\% with beta-blockers while the frequency is not defined for other classes of antihypertensives [5] and only few cases reports with antiepileptics [6-8]. People are not aware of the drug being accountable for causing or exacerbating sexual dysfunction; therefore, health care professionals need to have an open discussion with their patients about their sexual health in every visit for early detection of druginduced sexual dysfunction and its management [2].

An important first step in approaching all patients with a sexual problem is taking details of medical (medication and disease state), surgical, sexual and drug/substance abuse which is tedious [9]. In India, there are only two psychiatrists per 10 lakh population which is much less than the World Health Organisation (WHO) prescribed limit of 1:1000 [10]. Pharmacist being a member of the health care team can contribute to uplift the quality of life of patients. Therefore, an inter-professional collaboration might help in minimizing the burden on psychiatrists. There are few studies, especially in the Indian population, addressing drug-induced sexual dysfunction, and our study aimed to assess the role of clinical pharmacist in identification and management of drug-induced sexual dysfunction in collaboration with psychiatrist and also to determine the prevalence and pattern of drug-induced sexual dysfunction, identify nature and extend of drug-induced sexual dysfunction, and assess the pattern of management of drug-induced sexual dysfunction.

\section{MATERIALS AND METHODS}

\section{Study design/period}

This is a periodic prevalence interventional study carried out among inpatients and outpatients of the psychiatric department of a university hospital over a period of three months. Before commencing the study, approval from the Institutional Human Ethics Committee of JSS College of Pharmacy, Mysore, Karnataka was apprehended.

\section{Study criteria}

All patients aged $18 \mathrm{y}$ and above, with at least one medication for a week, were included in the study. Patients were excluded from the study if mentally retarded or had a medical condition with a significant cognitive impairment or meaningful discussion between the patient and the 
researcher was not possible, patients with severe and prolonged physical disability, patients with alcohol or other drug/substance abuse, patients who were receiving alternate system of medicine, patients having sexual dysfunction due to other causes apart from drugs, elderly patients aged $\geq 65 \mathrm{y}$ and menopaused women.

\section{Study procedure}

Patients visited/admitted to the psychiatry department were reviewed and those who met study criteria were enrolled after the informed consent. All subjects were screened for sexual dysfunction using the Arizona Sexual Experiences Scale (ASEX) by the study pharmacists. The detailed medical (medication and disease state), surgical, and the status of sexual health of patients were taken by the study pharmacists to rule out other possible causes of sexual dysfunction. Suspected cases of sexual dysfunction were referred to a psychiatrist for diagnosis, classification and identification of the possible causes for sexual dysfunction. Once the diagnosis was confirmed, an appropriate treatment strategy was developed by the psychiatrists in collaboration with study pharmacists. All the necessary data such as patient demographics, drug history, types of sexual dysfunction and management patterns were documented. Prevalence of drug-induced sexual dysfunction was calculated by taking patients who were suspected of having any sexual dysfunction caused by any class of pharmacological agents as the numerator and the total number of the patients who were enrolled in the study as the denominator.

\section{RESULTS}

Of the 100 patients reviewed, only $50 \%$ of subjects met the study criteria and were enrolled in the study, in which 18 (36\%) were men and $32(64 \%)$ were women. The mean age of the patients was 34.5 (range 20-52) years. Depression (42\%) was the most common clinical diagnosis among the study patients. Sociodemographic details of the patients were presented in table 1.

Table 1: Sociodemographic details of the patients

\begin{tabular}{|c|c|c|c|}
\hline Demographic characteristics & Patients with SD* $(\mathrm{N}=8)[\mathrm{n}(\%)]$ & Patients without SD* $(\mathrm{N}=42)$ [n (\%)] & Total patients $(\mathrm{N}=50)[\mathrm{n}(\%)]$ \\
\hline \multicolumn{4}{|l|}{ Gender: } \\
\hline Male & $5(62.5)$ & $13(31)$ & $18(36)$ \\
\hline Female & $3(37.5)$ & $29(69)$ & $32(64)$ \\
\hline \multicolumn{4}{|l|}{ Age group: } \\
\hline $20-24$ & $1(12.5)$ & $4(9.5)$ & $5(10)$ \\
\hline $25-29$ & 0 & $10(23.8)$ & $10(20)$ \\
\hline $30-34$ & $2(25)$ & $13(30.9)$ & $15(30)$ \\
\hline $35-39$ & $1(12.5)$ & $3(7.3)$ & $4(8)$ \\
\hline $40-44$ & $1(12.5)$ & $7(16.6)$ & $8(16)$ \\
\hline $45-49$ & $2(25)$ & $5(11.9)$ & $7(14)$ \\
\hline $50-54$ & $1(12.5)$ & 0 & $1(2)$ \\
\hline \multicolumn{4}{|l|}{ Diagnosis: } \\
\hline Depression & $4(50)$ & $17(40.5)$ & $21(42)$ \\
\hline Bipolar affective disorder & $2(25)$ & $7(16.7)$ & $9(18)$ \\
\hline Schizophrenia & $1(12.5)$ & $3(7.1)$ & $4(8)$ \\
\hline Somatoform disorder & $1(12.5)$ & 0 & $1(2)$ \\
\hline Others & 0 & $15(35.7) * *$ & $15(30)$ \\
\hline \multicolumn{4}{|l|}{ Marital status: } \\
\hline Married & $7(87.5)$ & $34(81)$ & $41(82)$ \\
\hline Unmarried & $1(12.5)$ & $8(19)$ & $9(18)$ \\
\hline \multicolumn{4}{|l|}{ Family type: } \\
\hline Joint & $4(50)$ & $11(26.2)$ & $15(30)$ \\
\hline Nuclear & $4(50)$ & $31(73.8)$ & $35(70)$ \\
\hline \multicolumn{4}{|l|}{ Residential area: } \\
\hline Rural & $2(25)$ & $27(64.3)$ & $29(58)$ \\
\hline Urban & $6(75)$ & $15(35.7)$ & $21(42)$ \\
\hline \multicolumn{4}{|l|}{ Education: } \\
\hline Postgraduate or Professional & $1(12.5)$ & $5(11.9)$ & $6(12)$ \\
\hline degree & $2(25)$ & $9(21.4)$ & $11(22)$ \\
\hline Graduate degree & $3(37.5)$ & $7(16.7)$ & $10(20)$ \\
\hline High secondary certificate & 0 & $10(23.8)$ & $10(20)$ \\
\hline Higher school certificate & 0 & $6(14.3)$ & $6(12)$ \\
\hline Middle school certificate & 0 & $2(4.8)$ & $2(4)$ \\
\hline $\begin{array}{l}\text { Literate, less than middle } \\
\text { school certificate }\end{array}$ & $2(25)$ & $3(7.1)$ & $5(10)$ \\
\hline \multicolumn{4}{|l|}{ Illiterate } \\
\hline \multicolumn{4}{|l|}{ Occupation: } \\
\hline Professional & $3(37.5)$ & $4(9.5)$ & $7(14)$ \\
\hline Semi-professional & 0 & 0 & 0 \\
\hline Arthematic skill jobs & 0 & 0 & 0 \\
\hline Skilled worker & 0 & $3(7.1)$ & $3(6)$ \\
\hline Semi-skilled worker & $3(37.5)$ & $10(23.8)$ & $13(26)$ \\
\hline Unskilled worker & $2(25)$ & $6(14.3)$ & $8(16)$ \\
\hline Unemployed & 0 & $19(45.2)$ & $19(38)$ \\
\hline \multicolumn{4}{|l|}{ Comorbidity: } \\
\hline Yes & $3(37.5) \#$ & $6(14.3)^{\$}$ & $9(18)$ \\
\hline No & $5(62.5)$ & $36(85.7)$ & $41(82)$ \\
\hline
\end{tabular}

SD*-Sexual dysfunction, **-Mania $(\mathrm{n}=6)$, Obsessive compulsion disorder $(\mathrm{n}=5)$, Seizure disorder $(\mathrm{n}=1)$, Psychotic disorder $(\mathrm{n}=1)$, Panic disorder $(n=1)$, Dysthymia with migraine $(n=1)$, \#-Hypertension $(n=1)$, Hypertension with Diabetes Mellitus with Chronic Kidney Disease ( $=1)$, Hypertension with Hypothyroidism $(n=1)$, \$-Hypothyroidism $(n=1)$, Seizure disorder $(n=1)$, Haemorrhoid $(n=1)$, Migraine $(n=1)$, Diabetes Mellitus ( $n=1)$, Hypertension $(n=1)$. 
A total of eight drug-induced sexual dysfunctions were identified among 50 patients. The overall prevalence of drug-induced sexual dysfunction was $16 \%$ and higher incidence was observed in men $[\mathrm{n}=5(62.5 \%)]$ compared to women $[\mathrm{n}=3(37.5 \%)]$. The pattern of sexual dysfunction existed in men and women was shown in fig. 1.

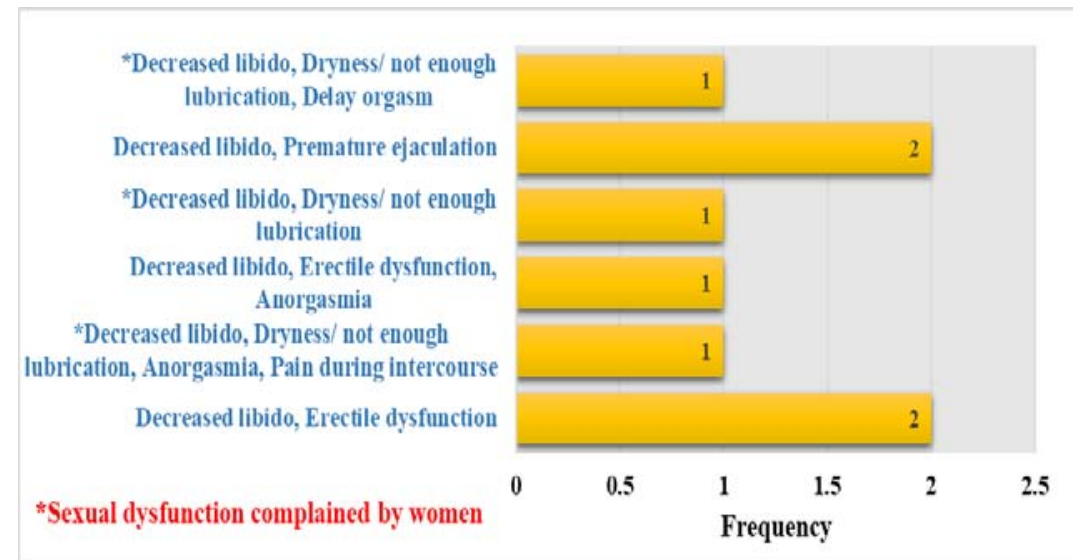

Fig. 1: Pattern of sexual dysfunction

Decreased libido [ $\mathrm{n}=8(40 \%)]$ was the most prominently observed drug-induced sexual dysfunction, followed by erectile dysfunction and dryness/not enough lubrication $[\mathrm{n}=3(15 \%)$ each], while premature ejaculation and anorgasmia with same frequency [n = $2(10 \%)]$. Also, delay orgasm and pain during intercourse with the same magnitude [ $\mathrm{n}=$ $1(5 \%)]$. Antidepressant [ $\mathrm{n}=3(50 \%)]$ was the most common class of drug implicated in sexual dysfunction, followed by antipsychotic [n $=2$ (33\%)], and antiepileptic [ $\mathrm{n}=1(17 \%)]$. Escitalopram [ $=3(37.5 \%)]$ was found to be contributing most to sexual dysfunction, while Desvenlafaxine, Duloxetine, Risperidone, Haloperidol and
Oxcarbamazepine were found to be of same magnitude [ $\mathrm{n}=1(12.5 \%)]$. Decreased libido was more frequently reported with all above mention drugs. Anorgasmia, erectile dysfunction, dryness/not enough lubrication and pain during intercourse were associated with Escitalopram. Similarly, anorgasmia and erectile dysfunction were found with Duloxetine and erectile dysfunction was found out with Desvenlafaxine. Delay orgasm and dryness/not enough lubrication with Oxcarbamazepine, while premature ejaculation was found with both Haloperidol and Risperidone. The nature and extend of drug-induced sexual dysfunction were depicted in fig. 2 .

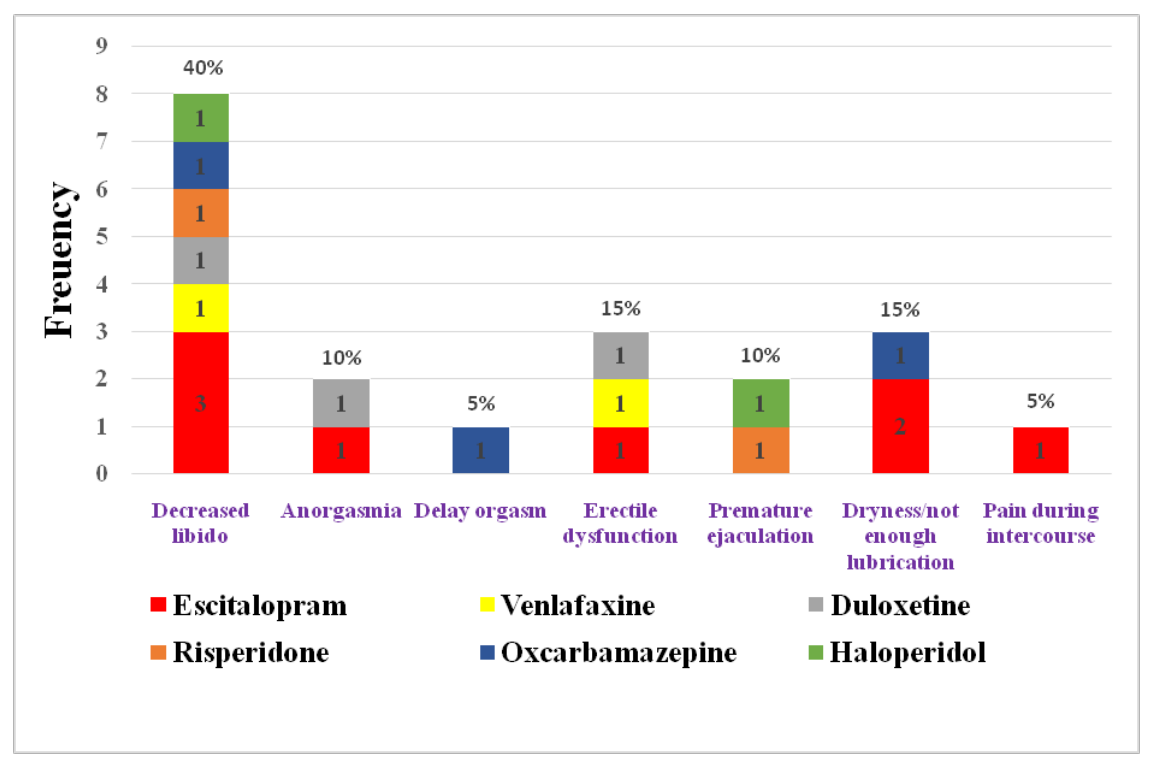

Fig. 2: Nature and extend of drug-induced sexual dysfunction

For the management of drug-induced sexual dysfunction among eight cases; in five cases, pharmacological agents were prescribed, those were Tadalafil $[\mathrm{n}=1(20 \%)]$, Tadalafil+Dapoxetine $[\mathrm{n}=2(40 \%)]$ and vaginal lubricant $[\mathrm{n}=2(40 \%)]$. While, "no change" of suspected drugs [n = 2 (25\%); as patients were well maintained on prescribed drug regimen, so psychiatrist gave a call not to stop or switch to other classes of drug], "dose altered" of suspected drug [n = $1(12.5 \%)]$ and "stopped" suspected drugs $[\mathrm{n}=2(25 \%)]$ were the interventions taken in those five cases. Whereas, in the other three cases, "as patients didn't experience sexual problem to the extent, where they felt the need of having a pharmacological agent", therefore denied the suggested treatment. Among remaining 3 cases, in 2, there were "no change" [ $n=2(25 \%)]$ in suspected drug responsible for sexual dysfunction; while in 1 case, the suspected drug was "stopped" [n $=1$ $(12.5 \%)]$. The overall picture of action taken for suspected drug responsible for sexual dysfunction was depicted in fig. 3 . 


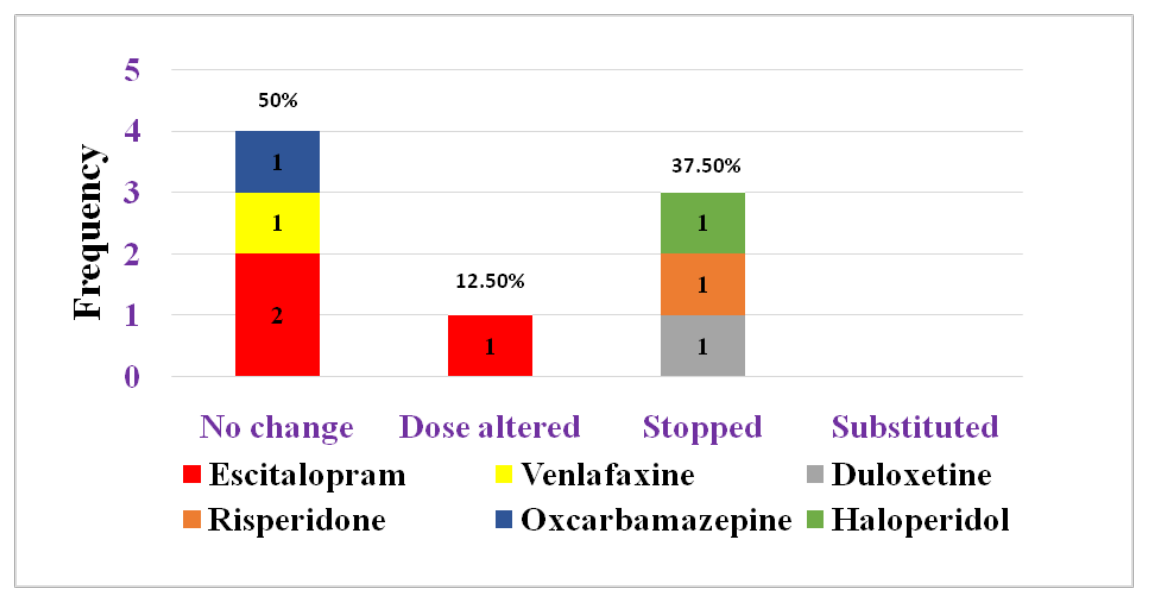

Fig. 3: Overall action was taken for suspected drug causing sexual dysfunction

\section{DISCUSSION}

Even though, many classes of drugs adversely affecting sexual functions like libido, erection, ejaculation and orgasm have been documented [11], statistically significant studies are still lacking [12]. Therefore, drug-induced sexual dysfunction was a relatively common yet poorly understood clinical problem. In this study, the prevalence of drug-induced sexual dysfunction was $16 \%$ and a higher incidence was observed in men (62.5\%) compared to women (37.5\%) which were just opposite to a study conducted by Jisha M. Lucca et al. where the higher incidence of drug-induced sexual dysfunction was in women (70.88\%) [4]. This might be partially due to the social conservative norm, where women were uncomfortable to discuss sexual problems with the researcher (researcher was male) and might also be due to a smaller number of patients being enrolled in the study. Another possible reason for the change in incidence may due to the difference in the scale used in the study. Depression (42\%) was the most common clinical diagnosis among the study patients; this finding correlates with Lucca et al.'s report (2016). According to WHO also, depression was the most common psychiatric diagnosis worldwide [13]. A higher incidence of druginduced sexual dysfunction was observed in married $(87.5 \%)$ patients. It might be partially due to a more reliable assessment of sexual function in married patients compare to unmarried patients.

In this study, an antidepressant (50\%) was the most common class of drug implicating in sexual dysfunction. However, different rates have been reported by other authors; Gregorian et al. [12] indicated rates of sexual dysfunction between $30 \%$ to $60 \%$, while Clayton et al. [14] reported prevalence between $36 \%$ to $43 \%$ with antidepressants. The variation in prevalence rates might be due to different methodological approaches adopted by different studies. Escitalopram $(37.5 \%)$ was contributing most to sexual dysfunction, while Desvenlafaxine (precursor of venlafaxine) and Duloxetine were found to be of the same magnitude (12.5\%). Serretti and Chiesa reported the percentage of sexual dysfunction as $37 \%$ with Escitalopram, $42 \%$ with Duloxetine and $80 \%$ with Venlafaxine [15]. Escitalopram was having the same percentage of prevalence, while percentage differ with Duloxetine and Venlafaxine because only 2 patients were suspected drug-induced sexual dysfunction from each drug in this study, among eight drug-induced sexual dysfunction cases. Decreased libido, anorgasmia, erectile dysfunction, dryness/not enough lubrication and pain during intercourse were associated with Escitalopram, while decreased libido, anorgasmia and erectile dysfunction with Duloxetine; and with desvenlafaxine; decreased libido and erectile dysfunction were reported in this study. Similar sexual dysfunctions were reported by A. La Torre et al. among patients on SSRIs and SNRIs [16].

Antipsychotic drugs (33.33\%) account for sexual dysfunction in this study. The prevalence rate varies widely among studies carried out by different authors for antipsychotic-induced sexual dysfunction. In a study by Baggaley, $30 \%$ to $80 \%$ of female schizophrenic patients and $45 \%$ to $80 \%$ of male schizophrenic patients reported impaired sexual functioning [17]. Likewise, Macdonald et al. reported $82 \%$ of men and $96 \%$ of women [18] and Fan X et al. reported between $65 \%$ and $94 \%$ for both sexes [19]. Some studies have reported lower rates: approximately $58 \%$ of men and $33 \%$ of women in a study by Ghadirian et al. [20], $59.3 \%$ of men and $49.1 \%$ of women in the study by Fujii et al. [21], while only $10 \%$ (for both sexes) in the research by Knegtering et al. [22]. The variation in prevalence rates among the studies was mainly due to different methodological approaches adopted by different studies; like studies that relied only on spontaneous reporting of side effects, report low rates of sexual dysfunction, while studies using structured interviews or questionnaires show higher rates of sexual dysfunction. Also, some researchers included iatrogenic endocrine disorders (amenorrhea, galactorrhoea and gynecomastia) as sexual dysfunction which is not termed under sexual dysfunction as per ICD-10, DSM-IV-TR, and therefore, may have affected the data on prevalence rates. Sexual dysfunction documented as antipsychotic-induced includes, decrease libido, erectile dysfunction, delay orgasm, anorgasmia, and ejaculation disorders (delayed or inhibited ejaculation, retrograde ejaculation, spontaneous ejaculation in the absence of sexual stimulation, decreased ejaculatory volume) [23-25]. In our study, the prevalence of sexual dysfunction with risperidone and haloperidol is $12.5 \%$ each; decreased libido and premature ejaculation were found to be associated with them. Dossenbach et al. reported the prevalence rate of $71 \%$ for haloperidol and $68 \%$ for risperidone [26]. Percentage variation exists while comparing the studies. This might be because only 2 patients were suspected as antipsychoticinduced sexual dysfunction in our study.

Antiepileptics or mood stabilizers have been documented to cause sexual dysfunction. Since epilepsy itself was a prominent risk factor for the development of sexual dysfunction; therefore, for patients who were on the anti-epileptic drug, it was difficult to rule out whether sexual dysfunction was a result of disease or induced by the anti-epileptic drug [27]. In this study, a patient diagnosed with Bipolar Affective Disorder was suspected as Oxcarbamazepine $(12.5 \%)$ induced sexual dysfunction, who complains of decreased libido, delay orgasm and dryness/not enough lubrication. In contrast to the findings of other studies, only some case reports of dosedependent oxcarbazepine-related anorgasmia and retrograde ejaculation had been published [6-8].

The role of clinical pharmacists in this study were: (1) To screen patients using ASEX for sexual dysfunction, take precise medical, medication, surgical history, and gather information on retrospective and present status of sexual function by interviewing patient; (2) To educate patients about their medical condition, medication and importance of its adherence, possibility of drug causing sexual dysfunction and essence of discussing their sexual health with doctors in every visit in order to detect sexual 
dysfunction as early as possible and to be treated on time, so that quality of life can be enhanced; (3) To convey patient's abovementioned details to psychiatrist and suggest possibility of a drug for causing sexual dysfunction based on sexual function before and after the consumption of suspected drug in enrolled patient who were screened positive for sexual dysfunction by ASEX; (4) To make final confirmation of drug-induced sexual dysfunction by collaborating with psychiatrist.

Psychiatrists expressed their satisfaction for the work, done in collaboration with clinical pharmacists (studying pharmacists) and with its results in detecting and managing drug-induced sexual dysfunction, as it gave aid to better patient care as a team. Likewise, patients appreciated for counseling them about their disease, medication, the importance of its adherence, the possibility of the drug causing sexual dysfunction and essence of talking about their sexual health with doctors in every visit to detect sexual dysfunction as early as possible and manage the same on a timely manner for the better quality of life.

\section{Limitations of the study}

The Limitations in this study were: (1) There were no documented baseline sexual function of any reviewed patients before starting the drug therapy; (2) The information on sexual function before starting drugs were collected by interviewing patients retrospectively, so chances of bias from patient side; (3) India being country of diversity in custom, culture norms and value, society being conservative, many patients were not willing to discuss their sexual health with health care professionals because of which the study might have missed many cases of drug-induced sexual dysfunction and hence low prevalence rate compared to other studies. This was the main challenge faced by researchers in this study and the same was reported by other authors who conducted a study on sexual dysfunction (Jisha M. Luccaa et al. 2016, Chukwujekwu Chidozie 2017 [26]).

\section{CONCLUSION}

Medical practitioners should initiate to talk with patients about their sexual health before starting any drug therapy. Baseline sexual function and sexual function of the patient in every visit should be documented using the appropriate scale as a part of the general examination to rule out this burdensome adverse effect of the drug as early as possible. Clinical pharmacists can play a role in such documentation and give a helping hand to medical practitioners to provide better patient care. This way it might help to carry out the prospective study, which may yield evidence-based statistically significant results nearly within the same narrow range though studies are carried out by different authors in different places and time, and may reveal answers of many mysterious questions in this arena of drug-induced sexual dysfunction.

\section{ACKNOWLEDGMENT}

Authors from the clinical pharmacy department thanks wholeheartedly Late. Dr Suma for her kindly cooperation during the study. We also express sincere thanks to the staff and postgraduate students of the Department of Psychiatry and Department of Clinical Pharmacy, JSS Hospital for sharing platform and assisting us directly or indirectly for completion of this study.

\section{FINANCIAL SUPPORT}

Nil

\section{AUTHORS CONTRIBUTIONS}

Dr Bilesh Shakya, Dr Tirin Babu, Dr Mohamed Shafi P and Dr Vemuri Tejasriwere involved in the collection of clinical details of the patients, literature search and preparation of the manuscript. DR Juny Sebastian, Dr Shivananda J Manohar and DR Jisha M Lucca designed the study, supervised the manuscript preparation and reviewed the manuscript.

\section{CONFLICTS OF INTERESTS}

Authors declare no conflicts of interest.

\section{REFERENCES}

1. Chunder R. Sexual dysfunction: an approach for the pharmacist. SA Pharm J 2011;78:18-21.

2. Mkele G. A review of medicines that affect sexual performance. SA Pharm J 2014;81:34-7.

3. Laumann EO, Paik A, Rosen RC. Sexual dysfunction in the United States: prevalence and predictors. JAMA 1999;281:53744.

4. Lucca JM, Ramesh M, Ram D, Kurian J, Mathew N. Psychotropic medication-induced sexual dysfunction and its interference with patient's daily performance: a cross-sectional study. Egyptian J Psychiatry 2016;37:36.

5. Conaglen HM, Conaglen JV. Drug-induced sexual dysfunction in men and women. Aust Prescr 2013;36:42.

6. Boora K, Chiappone K, Dubovsky SL. Oxcarbazepine-induced reversible anorgasmia and ejaculatory failure: a case report. Prim Care Companion J Clin Psychiatry 2009;11:173-4.

7. Calabro RS, Ferlazzo E, Italiano D, Bramanti P. Dose-dependent oxcarbazepine-related anorgasmia. Epilepsy Behav 2010; 17:287-8.

8. Calabro RS, Italiano D, Pollicino P, Bramanti P. Oxcarbazepinerelated retrograde ejaculation. Epilepsy Behav 2012;25:174-5.

9. Martin Morales A, Ibanez J, Machuca M, Pol Yanguas E, Schnetzler G, Renedo VP. The EPIFARM study: an observational study in 574 community pharmacies in Spain characterizing patient profiles of men asking for erectile dysfunction medication. J Sex Med 2010;7:3153-60.

10. Mohandas E. Roadmap to Indian psychiatry. Indian J Psychiatry 2009;51:173.

11. Goldstein I, Krane RJ. Drug-induced sexual dysfunction. World J Urol 1983;1:239-43.

12. Gregorian Jr RS, Golden KA, Bahce A, Goodman C, Kwong WJ, Khan ZM. Antidepressant-induced sexual dysfunction. Ann Pharmacother 2002;36:1577-89.

13. Lucca JM, Kurian J, Ramesh M, Ram D. Appraisal of clinical pharmacy services in the mental health unit of a South Indian tertiary care hospital. World J Pharm Pharm Sci 2014;3:780-91.

14. Clayton AH, Pradko JF, Croft HA, Montano CB, Leadbetter RA, Bolden Watson $\mathrm{C}$, et al. Prevalence of sexual dysfunction among newer antidepressants. J Clin Psychiatry 2002;63:357-66.

15. Serretti A, Chiesa A. Antidepressivi e disfunzione sessuale: epidemiologia, meccanismi e strategie di trattamento. Giornale Italiano Psicopatologia 2010;16:104-13.

16. La Torre A, Giupponi G, Duffy DM, Pompili M, Grozinger M, Kapfhammer HP, et al. Sexual dysfunction related to psychotropic drugs: a critical review-part I: antidepressants. Pharmacopsychiatry 2013;46:191-9.

17. Baggaley M. Sexual dysfunction in schizophrenia: focus on recent evidence. Human psychopharmacology. Hum Psychopharmacol 2008;23:201-9.

18. Macdonald S, Halliday J, MacEwan T, Sharkey V, Farrington S, Wall S, et al. Nithsdale schizophrenia surveys 24:sexual dysfunction: case-control study. Br J Psychiatry 2003;182:50-6.

19. Fan X, Henderson DC, Chiang E, Briggs LB, Freudenreich O, Evins $\mathrm{AE}$, et al. Sexual functioning, psychopathology and quality of life in patients with schizophrenia. Schizophr Res 2007;94:119-27.

20. Ghadirian AM, Chouinard G, Annable L. Sexual dysfunction and plasma prolactin levels in neuroleptic-treated schizophrenic outpatients. J Nerv Ment Dis 1982;170:463-7.

21. Fujii A, Yasui Furukori N, Sugawara N, Sato Y, Nakagami T, Saito $\mathrm{M}$, et al. Sexual dysfunction in Japanese patients with schizophrenia treated with antipsychotics. Prog Neuropsychopharmacol Biol Psychiatry 2010;34:288-93.

22. Knegtering H, Blijd C, Boks M. Sexual dysfunction and prolactin levels in patients using risperidone or olanzapine. Schizophr Res 2000;41:196.

23. La Torre A, Conca A, Duffy D, Giupponi G, Pompili M, Grozinger M. Sexual dysfunction related to psychotropic drugs: a critical review part II: antipsychotics. Pharmacopsychiatry 2013;46:201-8.

24. Patnaik S, Polimati H, Pragada R. Erectile dysfunction and its pharmacology: an overview. Asian J Pharm Clin Res 2017;10:17-23. 
25. Shekar D, Vazir M, Kempanna B, Miryala S, Subedi A. Effect of yohimbine on clomipramine-induced sexual dysfunction in male rats. Asian J Pharm Clin Res 2017;10:92.

26. Dossenbach M, Dyachkova Y, Pirildar S, Anders M, Khalil A, Araszkiewicz A, et al. Effects of atypical and typical antipsychotic treatments on sexual function in patients with schizophrenia: 12-month results from the intercontinental schizophrenia outpatient health outcomes (IC-SOHO) study. Eur Psychiatry 2006;21:251-8.

27. Calabro RS, Marino S, Bramanti P. Sexual and reproductive dysfunction associated with antiepileptic drug use in men with epilepsy. Expert Rev Neurother 2011;11:887-95. 